\title{
Stigma Experiences of Psychiatric Nurses and Coping Strategies: A Qualitative Study
}

\author{
Sibel Çaynak ${ }^{1} \mathbb{D}$, illkay Keser ${ }^{1 *}$ (D) and ilhan Günbayi ${ }^{2} \mathbb{D}$ \\ ${ }^{1}$ Department of Psychiatric Nursing, Faculty of Nursing, Akdeniz University, Antalya, Turkey \\ ${ }^{2}$ Department of Educational Sciences and Department of Educational Administration, Faculty of Education, Akdeniz \\ University, Antalya, Turkey
}

*Corresponding author: Dr. Ilkay Keser, Assistant Professor, Department of Psychiatric Nursing, Faculty of Nursing, Akdeniz University, Antalya 07058, Turkey, Tel: +90506-584-1675

\section{Introduction}

\section{The effects of stigma (and stereotypes) on people with mental illness}

Individuals with mental disorders have been stigmatized from the past to the present. This situation continues to negatively affect the quality of care and the quality of life by keeping a large number of patients out of seeking appropriate professional help [1]. Individuals with mental disorders are very sensitive to the attitudes of health staff. Negative attitudes of health workers may be an important factor negatively affecting patients' ability to receive needed professional help and the guidance of them [2]. Individuals with mental illness are subject to social isolation, inability to enter work, financial difficulties, housing and poor living conditions due to stigma. As a result of this, problems such as loss of self-confidence in individuals, embarrassment, deterioration in domestic relationships and problems of harmony with society arise. Because of stigma, both individuals with mental illness and their caregivers are affected psychosocially [2-5].

Stigma towards mental illness can be done by society as well as by health workers. In the systematic review, which evaluated the stigma of mental illness and patients, it was found that the health personnel working in health education and institutions in Turkey did not show any change in the last 10 years, and that they took a rejecting and exclusionary approach [6]. A study with 1414 psychiatrists abroad the stigma States of Psychia- trists against individuals diagnosed with schizophrenia were examined and it was found that there was stigma in psychiatrists for individuals diagnosed with schizophrenia [7]. In a study conducted with 312 individuals in a city center, fear and exclusionary behavior towards mental illness were determined [8].

\section{The effects of stigma in healthcare professionals}

Individual beliefs, personal characteristics are important determinants of individuals' attitudes towards individuals with mental illness [9]. The opinions of the nurses and physicians encountering patients with mental disorders about them are very important in terms of reflecting their attitudes and behaviors towards these patients $[10,11]$.

Negative attitudes that cause stigmatization stem from stereotypes [12]. The most common example of stereotyping for patients with mental disorders is the opinion that individuals with mental disorders are dangerous [11-14]. According to different studies in Turkey, this kind of stereotyping can be observed in health staff. It was stated that nurses refrained from having close relationships with patients with mental disorders or found them aggressive $[10,15]$. It was emphasized that non-psychiatric health workers did not have positive attitudes towards patients with mental disorders [16]. In some studies, it was stated that health care professionals from other fields may discredit the scientific or therapeutic effectiveness of psychiatry [10]. Department of psychiatry and healthcare professionals working in the

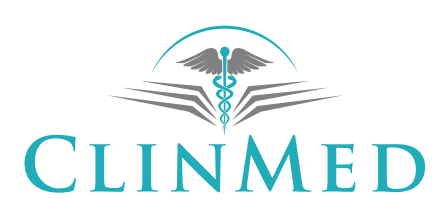

INTERNATIONAL LIBRARY 
department are held separate due to the characteristic of the patient group receiving service and thus, cause negative view points. Compared to her departments, there is a decrease in value and healthcare professionals refuse to build a career in this department [17].

\section{On the effects of stigma on Individuals' choice of psychiatry as an area of specialization}

Requirements of socioculturel, economical and social needs are determinant of preferring the mental health working area. Apart from that environmental factors and personality structure are also effects the requested work area. In a study with mental health professionals, the reasons for psychiatrists leaving their specialty are expressed as having a low image in the community and being an area that is not respected among other doctors [18]. Similarly in consequences of search which carried out with psychiatry nurses, psychiatric nursing is the least preferred speciality in a reputable nursing branch. In the study, it is stated that nurses who care for them, such as patients and their families, may be exposed to stigma [19]. In a study conducted with undergraduate students, almost half of the students stated that psychiatric nurses were reliable, and the majority were competent in caring for mental health [20].

\section{Stigmatization of psychiatric nursing}

Working with stigmatized individuals may also be associated with stigmatization of psychiatric nurses [19]. The stigma of psychiatric nursing may be caused by factors such as lack of information regarding the psychiatric nursing roles and responsibilities, fear of the unknown, prejudice and association with mental health. Although in the literature there are studies addressing the mental illness of patients and their families on the subject of stigma [21-23], there are a limited number of studies demonstrating stigmatization status of psychiatric nurses [24]. It has beennoted in recent years that psychiatry and mental health nursing has been stigmatized by health professions working in other fields, as well as by the public and the media. One study determined that the negative images of psychiatry constituted a phenomenon for stigmatization.

In addition to this, in the media, mental health professionals are defined as controlling, not protecting professional boundaries, careless, and having mental illness themselves [25]. Halter [26] stated that the character of "Nurse Ratched" in the movie "One Flew over the Cuckoo's Nest" would cause psychiatric nurses to be misunderstood by the public [26]. In a study examining the effect of stigma on psychiatric nurses, women were found to be more stigmatized than men [27]. It is important that all specialties of the nursing profession are equally accepted, and addressing the issue of stigmatization with psychiatric nurses will increase awareness of this problem [28].
Although the results of different studies conducted with health professionals in psychiatry clinics indicate that employees experience fear of being stigmatized, there is no study directly identifying psychiatric nurses' stigmatization and their strategies for coping with this situation. In this context, the study aimed to draw attention to the stigmatization of psychiatric nurses by understanding and commenting their stigmatization experiences and their ways of coping with this situation.

\section{Methods}

\section{Model of the study}

The study is a qualitative explanatory case study with an embedded single case design [29]. Explanatory case study is descriptive and used forgiving information about a phonemena being experienced in a unit or units in a contex. It is defined as an embedded single case pattern, because it was performed in two sub-departments linked with one institution [30]. Besides, the study was subjected to Consolidated criteria for reporting qualitative studies (COREQ): 32-item checklist [31].

\section{Place of the study and study group}

The study was conducted in Akdeniz University Faculty of Medicine Psychiatry Service and the Alcohol and Substance Addiction Research and Application Center (ASARAC). The psychiatry clinic had a capacity of 30 beds and served with nine nurses and an open clinic of the University hospital where chronic psychiatric disorders were cared for. ASARAC was a unit where eight nurses served with 20 bed capacity and an application center where alcohol and substance addiction were cared for.

Six nurses from Psychiatric services and six from ASARAC were interviewed individually. Then a focus group interview from three nurses from Physiatric services and three from ASARAC were carried out. Individual interviews were carried out in meeting rooms in clinics and focus group interviews in meeting hall in ASARAC.

The meeting room was located inside the clinic and a place where individuals could express themselves in a relax atmosphere. The individual interview was carried out by sitting face to face and the focus group interview was carried out by using a round table sitting and creating time and opportunity for everyone to express themselves.

\section{Data Collection}

While determining the sample, qualitative research methods data saturation principle is essential [28]. Accordingly, as a result of the data obtained from individual interviews, sufficient information content was reached with twelve people and the study was completed based on the transcripts of those interviews. The data were collected through interviews with nurses using an individual in-depth interview technique; the Semi-Structured Interview Form. The data of the study 
Table 1: Semi-structured interview questions.

1. What are your thoughts about the department you work for?

2. What do you feel about providing care for individuals with mental disorders/addictions and working at this clinic?

3. What are different aspects of working in the department they work in compared to the other clinics?

4. How are the opinions of other individuals related to the department they work for?

5. Do medical staff from other fields comment on your working field?

6. Have you had any difficulty experienced in working the clinic? If you had difficulties, what would you do for strengthening you to cope with them?

7. What is being a nurse in your department like? Why?

were collected between June-July 2018 from 12 nurses working in both the psychiatry service of Akdeniz University Faculty of Medicine and the ASARAC and being willing to participate in the study. Written consent was obtained from the participants. The confidentiality principle was taken into consideration when collecting and keeping all the information about the participants. The codes were used instead of real names of the participants during the analysis of the interviews. During the interviews, the voice of the participants was recorded within the permission of them. It was also tried to keep away biases by researchers and be careful not to impose researchers' belief on others and researcher's beliefs were secondary and the participants thinking be what was required.

In the data collection, the information form including sociodemographic information of the participants was used before the interviews while the semi-structured interview form consisting of 7 questions (Table 1) which guided the interviews and helped to collect relevant information was used. Semi-structured interview form was prepared based on researcher's experiences, observations and relevant literature. Besides, the appropriateness of the semi-structured interview form was confirmed by two experts in the field of psychiatric nursing. A preliminary practice was applied to two nurses to evaluate the availability of the data collection form. Because no arrangement was made after the preliminary practice of the data collection form, the two nurses were also included in the study.

After the individual interviews, 3 questions were selected from the interview questions and focus group discussions were done with 6 nurses. If a focus group interview is to be conducted in qualitative research, it is not recommended to exceed 3 or 4 questions since there are more people in the interview and it will take longer [32]. From the semi-structured interview questions formed by reviewing the literature and obtaining expert opinion, the questions that were thought to provide data for the research and that would contribute more to the data obtained after the individual interview were preferred. All individuals were given the right to speak, respectively. The draw method was used to participate in the focus group meeting and the participants' consent was obtained. Focus group interview facilitates the utilization of interaction between individuals, group dynamic and obtaining profound data.

Detailed data obtained from focus group interviews were preferred because they would provide a solid basis for face to face interviews and questionnaires. Interviews were recorded via voice recorder, individual interviews lasted about half an hour and focus group interviews about two hours.

\section{Data Analysis}

In the process of data evaluation, the recordings were transcripted and obtained through combining the transcripts with observation notes. After transcription, interview transcripts were sent to all researchers and feedback from them. The nurses sociodemographic variables were examined as the means and numbers. NVIVO 10 package program was used in the analysis of the data; descriptive analysis was performed for the data obtained from the interviews. The interviewers' sayings were written down after listening from sound recorders and analyzed using the NVIVO software. Main themes and sub-themes concerning the analyses were determined. Data analysis aided by the use of a qualitative data analysis computer program called NVIVO began with repeated listenings and readings of interview conversations and transcripts, the purpose was to determine the essence of the phenomenon and structures of experiences of psychiatric nurses and their ways of coping with this situation. During data analysis, the data were organized categorically and chronically, reviewed repeatedly and continually coded and shown in tables. The analysis was conducted independently by each researcher. Two persons out of the researches performed coding in the contex within the scope of validity and reliability, the kappa coefficient was found as 0.944 . The kappa coefficient ranging between 0.81 and 1.00 is interpreted as a perfect fit [29].

\section{Results}

\section{Characteristics of the participants}

All of the 12 participant nurses were women and their average age was 43.25. While their average working year as a nurse was 22.5 years, their average working year in a psychiatric clinic was 8 years. $58.34 \%$ of the nurses had an associate degree; $33.33 \%$ of them had 
Table 2: Characteristics of the participants.

\begin{tabular}{|l|l|l|l|l|l|}
\hline Participants & Age & Gender & Education Status & $\begin{array}{l}\text { Professional } \\
\text { Experience }\end{array}$ & $\begin{array}{l}\text { Working Experience in Psychiatry } \\
\text { Clinic/ASARAC }\end{array}$ \\
\hline P1 & 38 & Female & Graduate & 17 year & 4 year \\
\hline P2 & 38 & Female & Graduate & 16 year & 8 year \\
\hline P3 & 39 & Female & Graduate & 20 year & 7 year \\
\hline P4 & 40 & Female & Associate degree & 21 year & 9 year \\
\hline P5 & 50 & Female & Associate degree & 26 year & 16 year \\
\hline P6 & 40 & Female & Graduate & 17 year & 8 year \\
\hline P7 & 43 & Female & Associate degree & 20 year & 13 year \\
\hline P8 & 46 & Female & High School & 25 year & 8 year \\
\hline P9 & 47 & Female & Associate degree & 29 year & 9 year \\
\hline P10 & 50 & Female & Associate degree & 30 year & 5 year \\
\hline P11 & 43 & Female & Associate degree & 24 year & 5 year \\
\hline P12 & 45 & Female & Associate degree & 25 year & 5 year \\
\hline & & & & & \\
\hline
\end{tabular}

a bachelor's degree; $8.33 \%$ of them were high school graduates (Table 2 ).

\section{Themes related to interview findings}

Findings obtained from the study were discussed under 7 main themes. 3 of these focus on individual's own feelings, thoughts and perceptions about working at psychiatry clinics, 2 focus on the struggles they faced and their coping mechanisms while other 2 focused on the feelings that the individual received from family or the social environment. As an addition to all these evaluations, a metaphoric analysis based on metaphoric images produced by participants was done to interpret the individuals' feelings and thoughts about working at psychiatry clinics.

\section{Meaning of working in the psychiatry clinic/ASAR- AC}

When the nurses who participated in the study were asked about the meaning of working in the psychiatric clinic/ASARAC, 4/12 of the participants stated that working in the clinic was a privileged condition and different from the other clinics. 4/12 of them stated that helping people and touching others' lives were of concern; $2 / 12$ of them defined this situation as pleasing. $2 / 12$ of them stated that they were aware of their personal, social and professional responsibilities; $1 / 12$ of them require professionalism. $1 / 12$ of them stated that they saw their profession as a mechanical work; $1 / 12$ of them stated that it had some aspects developing individuals.

Some of the participants' opinions on this subject were as follows:

"Working at a psychiatry clinic makes me happy..." (P1).

"I started understanding people faster after working at the psychiatry clinic" (P2).
"Psychiatric clinic is a privileged clinic compared to other clinics, I have worked in a lot of departments before, the approach to individuals is different here, more professional approach is needed ..." (P4).

"...It only feels like a job for me, a job I have to do and I am doing, that's how I could describe" (P7).

Social responsibility, personal responsibility, I think this is the right place to be and working at for me" (P8).

"I've been here for 8.5 years. I love the psychiatry clinic more, it was one of the things I wanted to do. Fortunately, I have the chance for working in this place. I love the tone in this here, I love touch the lives of patients. In fact, the structure of the ASARAC is different from other places in terms of the course of the disease, premorbidity and postmorbidity, it is completely different and more exciting. It is especially important to be able to touch the lives of patients, especially young patients, so I feel both sorrow and joy, but l love working here" (P9).

\section{Feelings about working in the psychiatry clinic/ ASARAC}

When the participant nurses were asked about working in the psychiatric clinic/ASARAC, 7/12 of the participants stated that they were happy in their working environment; $6 / 12$ of them stated that they were experienced difficulties; $5 / 12$ of them stated they felt sorrow about their patients; $1 / 12$ of them stated that they felt dynamism; $1 / 12$ of them stated that they had occupational satisfaction; $1 / 12$ of them stated that they felt apprehension.

Some of the participants' opinions on this subject were as follows:

"...we feel very bad for some patients, however when they come here in a bad position and leave in good health, it makes me satisfied in terms of my job" (P1).

"Helping people makes us happy because they really 
need help and we're aware of it. Since we're aware of it, at least for me, this makes me happy" (P2).

"It's more lively and dynamic" (P5).

"Altough it's not physically demanding, I find it very demanding mentally" (P7).

"...Some patients could be frustrated, they might get obsessed with you and threaten you saying that they'll show you once they're outside" (P10).

"...I feel very happy and then there's a very demanding patient, or a patient coming back as if nothing changed, which makes us very sad from time to time, both for them and for the effort we showed..."(P12).

\section{Different aspects of working in other clinics in the psychiatry clinic/ASARAC}

The participating nurses were asked whether there were different aspects of working in the psychiatric clinic/ASARAC compared to working in other clinics. $7 / 12$ of them stated that the care and treatment were continuous; $6 / 12$ of them stated that it required more responsibility and job intensity was higher; $4 / 12$ of them stated that they experienced physical and psychological stress; $2 / 12$ of them stated that it provided personal gain to them; $2 / 12$ of them stated that there were recurrent hospitalizations.

Some of the participants' opinions were as follows:

"I've to check everything about the patients in the clinics. I have to take care of everything about the patients because the patients are not aware. Our patients do not acknowledge their diseases. Moreover, they directly come just like that. In other clinics, I do my job, provide care and exit from the room, but here it requires more responsibility to check medicine use, nutrition and night sleep of the patients" (P2).

"May be it's not physically demanding but we get mentally exhausted. We're assaulted from time to time, there're this kind of struggles..." (P4).

"...For example, I had no idea about making jewellery. I learned it here and applied it to patients. In a way, you gain and learn something for yourself while working with them. One of our friends who had no idea about baking became almost a master here. While helping the patient learn something, you make yourself gain it at the same time" (P5).

"Since the patients here tend to have addictions with repetitive natures, we see a lot of returns.... We had many patients who were admitted for more than one time in a year...." (P8).

"The work load is very high in this clinic in terms of physical and emotional compared to other departments. I worked in several places such as intensive care service, emergency service and ambulance, but the work load in here is hard for us in terms of psychological aspect.
You already know that, we need to have empathy skills from the beginning in our profession. We performed this job based on it, but we sometimes psychologically bottom out when we empathize here, however we recover quickly, of course ..." (P12).

\section{The opinions of other individuals related to work- ing in the psychiatry clinic/ASARAC}

The nurses who participated in the study were asked about the opinions of the relatives on working in the psychiatric clinic/ASARAC. 9/12 of the nurses stated that there were negative thoughts about the patient group; $7 / 12$ of them stated that there was some concerns the about the prone of the patients to violence; $3 / 12$ of them stated that there was a curiosity about the patient group and the clinic; $2 / 12$ of them stated that there was a thought about the probability of mental health deterioration in the health staff; $1 / 12$ of them stated that it was nice to be able to help the individuals; $1 / 12$ of them stated that there was a higher expectation for understanding and patience in their social relations.

Some of the participants' opinions were as follows:

"Sometimes our tolerance level is tested at home. My husband expects me to be more tolerant since I am a psychiatric nurse. They expect more from me because of my profession. They don't expect me to get angry fast, they expect more tolerance..." (P2).

"Some people ask me whether I would be inclined to have psychological problems myself since I am working here. Then there're others who really understand that people here are patients and we could help them" (P4).

"Yes, first of all my profession is asked. I say "I am a nurse", then they ask "where do you work?". When I say "I work in a psychiatric clinic", they say "you work with crazy people". This is the first statement, then they ask other questions such as "Is working with the patients in the clinic hard, aren't you afraid of them?, how can you work?" (P5).

"From time to time, some of our colleagues think that we are similar to the patients" (P6).

"...My family and friends always say that it's a hard place to work, maybe I should work somewhere else, asking why I won't transfer to a hospital, patients are assaulting me, what do we do, when they are having an episode and I should be very careful. Our family and friends are concerned about us" (P8).

\section{Opinions of the health care staff working outside the psychiatry clinic/ASARAC}

The nurses who participated in the study were asked about the opinions of the health personnel working outside the psychiatry clinic/ASARAC on the psychiatry clinic. $7 / 12$ of them reported that there was a high risk of being subjected to violence; $5 / 12$ of them reported that it was a clinic in which working was easy and work 
load was low; $4 / 12$ of them reported that it was a clinic in which working was hard; $2 / 12$ of them reported that the clinic should not be preferred; $1 / 12$ of them reported it was a clinic in which the patient group and environment were wondered; $1 / 12$ of them reported that it was a clinic in which the personnel were appreciated.

Some of the participants' opinions were as follows:

"There are some medical staff who are afraid of this place and the patients, who do not want to enter the clinic" (P1).

"We sometimes hear statements such as "you sit there, what are doing, nothing I'm sure you don't do much, the patients sleep". Others may think this kind of things, but the reality is different, it's hard when they get involved" (P4).

"...Other healthcare professionals do not really know what psychiatric nursing is or what we do here. They're very scared about us being assaulted or being hit. They usually ask how we endure this or if we have any security forces with us. They really don't know much about our response to patients" (P6).

"They think here is difficult to work. It is thought as a place open to attack. It is described as a place in which the persons do not come voluntarily, they are forced to come ..." (P7).

"...They understand us, telling what a nice job we have, how holy it is and how grateful they are to us"(P8).

\section{Difficulties about working in the psychiatry clinic/ ASARAC}

The nurses who participated in the study were asked about the difficulties they experienced in the clinic. 4/12 of them mentioned the difficulties in compliance with the clinic and patient group; 4/12 of them mentioned difficulties due to the need for knowledge; $3 / 12$ of them mentioned difficulties in providing security; 2/12 of them mentioned difficulties due to emotional overload; $2 / 12$ of them mentioned difficulties due to coping with the behaviors of patients, 2/12 of them mentioned difficulties due to staff shortage, 2/12 of them mentioned difficulties due to the lack of necessary support to solve problems by the administrators.

Some of the participants' opinions were as follows:

"I didn't experience much difficulty, but we had a certain number of employees because our clinic is two-storied. Especially after 00:00, we're the only nurses. We call a security staff or a personnel when we have a agitated patient, we experienced some problems until a security staff come" (P1).

"Yes, I experienced a lot in the beginning, because I had lots of difficulties with diagnoses. Sometimes, making diagnosis is very hard, different diagnoses can have very similar symptoms. It is necessary to under- stand it and communicate with the patient. I had many difficulties in the situations of agitation for determining the ways of controlling, calming and inseminating by talking, I don't have such difficulties now" (P4).

"We have serious problems about the financial dimension of the clinic because our legislation about mental health is far from being sufficient" (P5).

"...It's mentally wearing" (P8).

"Sometimes, although very small scaled, harassment from patients is inevitable. This might also be in the form of oral harassment" (P12).

\section{Practices to strengthen the coping strategies for experienced difficulties}

The nurses were asked about what are the probable practices that would strengthen the coping strategies for the experience difficulties in the clinic. 5/12 of them considered as gaining experience; $5 / 12$ of them considered as working in team collaboration; 5/12 of them considered as provision of necessary support by managers to solve the problems; $4 / 12$ of them considered as getting training; $2 / 12$ of them considered as sharing emotions and experiences; $1 / 12$ of them considered as fun activities to relax individuals.

Some of the participants' opinions were as follows:

"Having more staff members would be great relief to us, for example. Our department has only two-stories, we cannot suffice"(P2).

"I've really benefited from in-service trainings for the diagnoses, especially at the beginning. I still use the notes from these trainings when $i$ have difficulties to solve something, because we can forget some time later" (P4).

"...Practices, trainings, life experiences, all of them" (P7).

"There could be motivational programs to increase the motivation of the nurses working at such clinics" (P8).

"When you learn the control of the job and what you need to do, you can better overcome. We somehow have communication with the patients in last 8.5 years" (P9).

\section{Metaphors about working in the psychiatry clinic/ ASARAC}

The nurses who participated in the study were asked to liken the clinic with one thing, some of them produced similar metaphors while others produced different metaphors. 2/12 of them produced nature metaphors; $6 / 12$ of them produced human metaphor; $1 / 12$ of them produced a metaphysical element; $3 / 12$ of them produced object metaphors.

Some of the participants' opinions are as follows: 
"Kindergarten teacher, but large group" (P1).

"I think the clinic is similar to a bee" (P2).

"I think the clinic is similar to a tree" (P3).

"In psychiatry, saving a person going to a marsh, I don't know, maybe like a lifeguard" (P4).

"It is similar to parenthood" (P5).

"In general, I see them as blind, deaf and mute persons; I think a nurse is person who gives light to the patients with psychiatric disorders; a nurse shows the way, guides, touches the patients; a nurse is a light, lamb or an illuminator" (P6).

"It is similar to motherhood" (P7).

"Now, a mother, a mother with problematic children" (P8).

"Maybe because of my own health problem, I think the nurse who cared and helped me is similar to an angel when I was a child, it is super, awesome, I remember that touch, this profession is always on my mind just like that" (P9).

"I see them as a broken vase while I see us as a glue" (P10).

\section{"Gardener" (P11).}

"It may be something about help. I always think and feel of something in terms of energy. I always work on by feeling that way for a long time, in the meaning of giving them good energy" (P12).

\section{Discussion}

Within the scope of this study, the feelings, thoughts, difficulties related to working in psychiatry clinics and stigmatization status for working in psychiatry clinics by health workers in other fields of the nurses working in the psychiatry clinics, were evaluated; the striking results were obtained. The results of the study are important in terms of revealing the stigmatization experiences of the psychiatric nurses and their preferred ways to cope with this situation.

The findings of our study in which the stigmatization status of psychiatric nurses were evaluated comprehensively, were discussed under the topics of the feelings and thoughts of the nurses about working in the psychiatric clinic, the thoughts of the health staff in other fields about working in the psychiatric clinic; the difficulties experienced by the participants about working in a psychiatric clinic and their coping strategies and metaphors about working in the psychiatry clinic/ASARAC.

\section{Feelings and thoughts of the nurses about both the department they work for and providing psy- chiatric care}

The feelings that the nurses feel about their profession and the patient group are of great importance in providing quality care services and experiencing professional job satisfaction. When the participants were asked to express the meaning of working in a psychiatric clinic and their feelings about that, they often described it as a privilege to make a difference, to touch the lives of others and to help them and as a personality developing and pleasing condition. They also stated that they experienced difficulties, felt sorrow, had tremendous responsibilities and uneasiness; it required professionalism. Although nurses experienced sorrow and difficulties, they were generally satisfied with working in psychiatric clinics by experiencing happiness and professional satisfaction as a result of positive changes in the patient. Ünsal, et al. [30] reported that approximately $90 \%$ of the participants were satisfied with working in the psychiatric clinic, which is parallel with the of this study [30].

One participant mentioned about the meaning of working in a psychiatric clinic as professionalism. The improvement of professional behavior of psychiatric nurses by them is important in terms of improving the quality of care [31]. When the roles and responsibilities of psychiatric nurses are considered, it is an important finding that of a nurse associated working in the psychiatric clinic with professionalism. The fact that a nurse associated working in the psychiatry clinic with professionalism is an indicator of their awareness of their roles and responsibilities.

Although most of the participants emphasized that the care and treatment were continuous in the clinic, there were more responsibility and work load, they experienced physical and mental strain and there was reinstitutionalization, they also stated that they had the opportunity for positive personal gain. The roles and responsibilities of psychiatric nurses are different from other clinical nursing in terms of ensuring the therapeutic environment, occupational activities and patient interviews. In Turkey, the duties, authorities and responsibilities of the subspecialties of Mental Health and Disease Nursing as psychiatric clinical nursing, child and adolescent psychiatric nursing, consultation liaison psychiatric nursing, alcohol and drug addiction center nursing are defined in detail in Nursing Regulation [33]. In the regulation for psychiatric clinical nurse; nursing care, the participation in the implementation of medical diagnosis and treatment plan, training and consulting roles are given in detail. In this context, the continuity of care and treatment, higher responsibility and workload in our findings can be explained by the scope of the roles and responsibilities in the regulation.

Psychiatric nursing is one of the specialities of the nursing profession. In a study conducted with community mental health nurses, it was found that $36 \%$ of nurses experienced emotional exhaustion, $12 \%$ were alienated from themselves, and only $10 \%$ showed individual success [34]. Nurses working in psychiatry clinics 
experience high levels of stress [35]. It is thought that patients' witnessing traumatic life events, inability to control their thoughts and behaviors due to impaired mental and perceptual processes, and the risk of violence and suicide may cause changes in psychiatric nurses' feelings, thoughts and perceptions about the field. The fact that psychiatric nurses stated that they experienced difficulties and anxiety as a result of the study was in parallel with the findings of the literature.

The opinions of both social environment (Family, Friends, etc.) and the health workers in other fields about the department they work for

The participants mentioned that their relatives (families, friends, etc.) had worries about working in a psychiatry clinic such as negative opinions about the patient group, worries about the propensity for violence of the patients, curious questions about the patient group and the environment, the concerns about the patient group and their environment, and the concerns about the probability of mental health deterioration in time. They also stated that being able to help individuals with mental disorders was expressed as a good and appreciated situation. In a study conducted to determine the opinions of student nurses about psychiatric nursing course and the roles of psychiatric nurses, it was determined that the majority of the students did not want to work in psychiatry clinics because of both their prejudices about mental disorders and patients with mental disorders and their observations in the field of psychiatric nursing [36]. In another study conducted with psychiatric nurses, it was found that nurses feared about being stigmatized by their friends and family members; psychiatry service was frightening and insecure according to them [37]. In another study comparing the attitudes of health professionals working and not working in the field of mental health towards mental illness, the rate of health professionals working in other fields stigmatizing individuals with mental illness was high [36]. Results suggest that mental health trainees and professionals had less stigmatizing attitudes than did non-mental-health trainees and professionals. It is due to the perception of the society about psychiatric patients such as unpredictable and dangerous persons. Tendency to exclude is seen as a result of fear and perception of danger [37]. The negative thoughts and concerns in the study findings support the findings in the literature.

The participants stated that psychiatry clinics were mentioned as an application field with higher risk of being exposed to violence, a low workload, interesting patient group and environment. In parallel with these negative thoughts, they stated that the study of psychiatric clinics was considered as an area which cannot be preferred by themselves in the findings of this study, health workers in other fields stated that the workload was low in psychiatric clinics suggested that the roles and responsibilities of the psychiatric nurses were un- derestimated. Natan, et al. [38] reported that nurses working outside psychiatry clinics underestimated the roles and responsibilities of psychiatric nurses and this finding supports the findings of this study [39]. In another study, it was reported that the psychiatrists abandoned their profession because of the low image of the profession in the society and the lack of respect among the other doctors [19]. In a study conducted with medical students before and after they completed their psychiatry internship, it was found that there was a decrease in preference for psychiatry as an area of speciality after students completed their psychiatry internship [40]. The studies showed that the persons working in the psychiatry field were exposed to stigmatization by other health personnel. In this context, it is considered that the awareness of other medical staff about their negative attitudes towards disorders, individuals with mental disorders and their caregivers is an important factor for coping with stigmatization.

In general, psychiatric patients are thought to be aggressive and dangerous dangerous [1]. In the literature, it was stated that there was a high probability of occurrence of threats and violence in psychiatric clinics $[41,42]$. There were the findings which showed that psychiatric nurses were frequently exposed to physical and verbal assaults in these violence cases. In the study of Pekriz [43], the rate of experiencing at least one verbal assault by the nurses working in psychiatry services was 94.5\%; the rate of experiencing at least one physical attack by them was at least 79\% [44]. As a result of this our study, the fact that the nurses described working in psychiatry clinics and giving psychiatric care as a difficult and uneasy situation may be related to the thought in the society that psychiatric patients are dangerous and violent. The nurses' statements about experiencing difficulties in providing psychiatric care and uneasiness in the clinic support the findings of this study.

\section{Difficulties experienced by the nurses and their ways of coping with them}

The participants stated that they experienced different difficulties due to the patient, the clinical setting or themselves when they were providing psychiatric care. The nurses stated that they had difficulties in adaptation and needed information when they started working in the psychiatry clinic. In a study focusing on the experiences of psychiatric nurses in their first years in the profession, it was determined that the nurses could not understand mental disorders and communicate properly with the patients and had difficulties in coping strategies [38]. When the psychiatric clinic and patient characteristics were considered, this might be related to the lack of adaptation of the nurses who were new to the clinic.

The other problem experienced by the participants was to provide a safe environment [45]. The sense of 
safety and security is very important for both patients and employees in psychiatric clinics. So as to achieve the maximum quality of patient care, risks should be minimized and a safe patient care environment should be created [46]. Security/safety, which is one of the characteristics of the therapeutic environment, has the meaning of being away from danger and damages including physical and psychological damages [47]. The nurses' statements about experienced difficulties about ensuring and maintaining security revealed that there were security requirements.

Nursing which is one of the health professions, is a challenging profession that requires professional knowledge, skills as well as teamwork and communication skills. In this context, nurses face many stressors in their working environment, psychiatric nurses work in intense stressful environments [43]. Psychiatric nurses have to work more devoted in line with the needs and expectations of individuals with mental disorders and experience emotional overload. It was stated that exhaustion was more common in psychiatric nurses due to the physical characteristics of the environment, excess number of patients and the propensity for violence of the patients [48]. The emotional exhaustion scores of the mental health workers were found to be high in a different study about the emotional exhaustion in mental health workers [49]. In this study, it was found that working in the psychiatry clinic caused emotional overload and exhaustion. It is consistent with the literature that the participants share their mental aging and emotional overload. This similarity was associated with the patient group, their working conditions and individual characteristics of the staff.

The nurses were asked to report their methods for coping with the difficulties experienced in the psychiatry clinic. The nurses stated that gaining experience in the field, working in team, providing the necessary support by the managers to solve the problems, improving the knowledge and skills by training, sharing the feelings and experiences and doing fun activities for relaxation were the factors that facilitate coping with the difficulties in the psychiatric clinic. Gaining experience and training on a particular subject makes it easy to cope with problems by showing the right approach to the issue. Psychiatric nurses' ability to cope with problems and increase their resilience contributes to their self-perceptions and spiritual development and improves the quality of mental health care. Rime and Zech [50] stated that individuals needed to express their emotional life, communication was important to ensure this need [50]. Expressing the feelings and communication are a therapeutic process. In a study conducted with the psychiatric nurses in a psychiatric service, it was reported that the nurses had concerns about the roles and responsibilities of psychiatric nurses, such as communication, approach and making a mistake [35]. In a different study focusing on the experiences of the psychiatric nurses in their early years, it was found that the nurses were inadequate and had difficulties in terms of their roles and responsibilities [38]. The suggestions such as gaining experience, increasing knowledge and skills and sharing feelings and thoughts reported by the participants in order to enhance the coping was parallel with the findings in the literature.

Considering the characteristics of the patient group working in the psychiatry clinic, it can be said that psychiatric nurses may have difficulties at different points and their individual coping methods vary. In a study it is stated that nurses may experience compassion fatigue and inability to provide care to their patients when they cannot establish the balance between their personal and professional lives and neglect themselves [51]. Therefore, strategies have been developed to improve coping skills and to focus prevent or improve compassion fatigue [51,52]. Nurses training on these strategies and their use of their knowledge gains importance in terms of their coping skills [52].

\section{Metaphors about working in the psychiatry clinic/ ASARAC}

In qualitative research methods, metaphor is often used to describe issues since it provides better explanations for the situations that are to be expressed. Based on this idea, individuals in our research were asked to like their work in psychiatry clinic to something else, as a metaphor, so as to be able to revise their interpretation about working at a psychiatry clinic from a different perspective. In a study conducted with the caregivers of individuals with dementia, with the use of metaphors, the caregivers were asked what it was like to be caregivers and most of the answers included sacrificing individuals, babysitters and mothers [51]. In another study which was conducted with hospitalized children and adolescents, participants were asked to explain their perceptions about the nurses through metaphors and it was found that they used the expressions of healing, big sister, angel and health. The care-providing and health protective roles of the nurses were perceived as positive concepts and were associated with the category of participation in the medical diagnosis and treatment plan [53]. In this study, the nurses who participated in the study were asked to liken the clinic with one thing, some of them produced similar metaphors while others produced different metaphors, some of the nurses could respond immediately while others made a connection with what they likened after thinking a little bit. They likened it with mother, life-saving, parent, gardener, kindergarten teacher under the category of human; they did that because psychiatric patients, alcoholics and substance addicts need help and nurses provide professional help to these patients. The things that the individuals want to express through metaphor seem to be confirming their ideas about working at a psychiatry clinic which was included in theme one. The fact that 
individuals tend to use metaphors which embody the behavior of helping other individuals is thought to be related to the roles and responsibilities of nurses.

\section{Conclusion}

In conclusion, it was founded that the nurses experienced positive and negative feelings together about working in psychiatric clinics and giving psychiatric care; they experienced difficulties in some cases, they were subjected to stigmatization in different dimensions by health professionals in other fields. It was revealed that nurses should be strengthened and trained to cope with stigmatization. A common fight must be given by healthcare professionals to change the negative perceptions of psychiatry.

Although the stigmatization is known to have many adverse effects on patients with mental illness and their families, the stigmatization experiences of healthcare professionals who care for mental illness are ignored. Negative stereotypes must be removed by means of informing the society in the correct direction. Longterm and effective cooperation is vital for reducing the stigmatization of mental illnesses, individuals with mental illnesses and their families, as well as the healthcare professionals working in the are of mental health. We share the idea that progress in mental health services, sharing the successful cases with the public, reducing suicide rates, in creating the treatment acceptance and making the positive effects of the use of psychotherapeutic interventions in psychiatric treatment visible could be effective in decreasing the stigmatization towards the area of psychiatry and the healthcare professionals who are serving in this area. The roles and responsibilities taken by the nurses working among healthcare professionals for creating and maintaining therapeutic environments in psychiatric clinics and for planning and executing the care of individuals are very important in preventing stigmatization and making other healthcare professionals aware of them.

Changing the false beliefs and information in the society, recognizing both other individuals and nonhealth care workers' negative attitudes towards individuals with mental disorders by them is important to prevent the stigmatization of psychiatric care personnel and individuals with mental disorders. In line with these results, it is recommended to conduct activities in psychiatric clinics such as awareness-raising activities in patient groups and to develop supportive intervention programs in which nurses share their feelings, thoughts and experiences in order to reduce stigmatization.

\section{Limitation of the Study}

As the research is qualitative study with a case study design and even if the results are limited the sample of the study, it can be said that the study is original as it is the first study in Turkey to draw attention to the stig- matization of psychiatric nurses. It is considered that making more detailed studies in this field on the type of stigmatization, duration and stigmatization will be useful. In addition, it is thought that it will be useful to conduct studies to ensure that intervention programs implemented to reduce the stigmatization of psychiatric nurses.

\section{Acknowledgement}

We would like to thank the nurses who participated in this study for their contribution. In addition, we would like to thank Prof. Dr. Kadriye Buldukoglu who was the head of the Department of Psychiatric Nursing in Akdeniz University and who raised our awareness about the necessity of studying this subject by emphasizing the importance of it.

\section{Conflict of Interest}

The authors declare no conflict of interest.

\section{References}

1. Karagöl A, Deniz Ç, Murat B (2013) Public health approach for three dimensional stigmatization in mental disorders. Journal of Continuing Medical Education STED 22: 96.

2. Çam O, Bilge A (2013) The process of stigmatization, attitude, and belief about mental illness and patient in Turkey: A Systematic Review. Journal of Psychiatric Nursing, 91101.

3. Livingston JD, Boyd JE (2010) Correlates and consequences of internalized stigma for people living with mental illness: A systematic review and meta-analysis. Soc Sci Med 71: 2150-2161.

4. Watson AC, Fulambarker A, Kondrat DC, Holley LC, Kranke D (2017) Social work faculty and mental illness stigma. Journal of Social Work Educatıon 53: 174-186.

5. Özmen S, Erdem R (2018) Conceptual Framework of the stigmatization Suleyman Demirel University. The Journal of Faculty of Economics and Administrative Sciences 23: 185-208.

6. Arkan B, Bademli K, Çetinkaya Duman Z (2011) Attitudes of health professionals towards mental disorders: Studies in Turkey during the last decade. Current Approaches in Psychiatry 3: 214-231.

7. Loch AA, Hengartner MP, Guarniero FB, Lawson FL, Wang YP (2011) Psychiatrists' stigma towards individuals with schizophrenia. Rev Psiq Clín 38: 173-177.

8. Tümer A, Hebcan Örs S, Akpinar H (2019) Adults attitudes to mental diseases/patients. Life Skills Journal of Psychology 3: 139-147.

9. Egbe CO, Brooke-Sumner C, Kathree T, Selohilwe O, Thornicroft $\mathrm{G}$, et al. (2014) Psychiatric stigma and discrimination in South Africa: Perspectives from key stakeholders. BMC Psychiatry 14: 191.

10. Bağ B, Ekinci M (2005) Examining of attitudes towards mentally ill people in a sample health professionals working. Journal of Electronic Social Sciences 3: 107-127.

11. Özer Ü, Varlik C, Çeri V, İnce B, Arslan Delice M (2017) Change starts with us: Stigmatizing attitudes towards mental illnesses and the use of stigmatizing language among mental health professionals. The Journal of Psychiatry and 
Neurological Sciences 30: 224-232.

12. Avcil C, Bulut H, Hizli Sayar G (2016) Psychiatric disease and stigmatization. Üsküdar University Journal of Social Sciences, 175-202.

13. Szeto AC, Luong D, Dobson KS (2013) Does labeling matter? An examination of attitudes and perceptions of labels for mental disorders. Soc Psychiatry Psychiatr Epidemiol 48: 659-671.

14. Çam MO, Bilge A, Engin E, Akmeşe ZB, Turgut EÖ (2014) Investigating the effectiveness of education of the fight against stigma on mental illness to headmen. Journal of Psychiatric Nursing 5: 129-136.

15. Bahar A (2007) Schizophrenia and stigmatization. Journal of Firat Health Service 4: 101-110.

16. Yenilmez Ç, Ayranci Ü, Kaptanoğlu C (2002) Attitudes of physicians in primary health care institutions to psychiatric service, diagnosis and treatment in Eskişehir. Turkish Journal of Psychiatry 4: 14-24.

17. Wigney T, Parker G (2008) Factors encouraging medical students to a career in psychiatry: Qualitative analysis. Aust N Z J Psychiatry 42: 520-525.

18. Lambert TW, Turner G, Fazel S, Goldacre MJ (2006) Reasons why some UK medical graduates who initially choose psychiatry do not pursue it as a long-term career. Psychol Med 36: 679-684.

19. Halter MJ (2008) Perceived characteristics of psychiatric nurses: Stigma by association. Arch Psychiatr Nurs 22: 2026.

20. Wantz R, Firmin M, Stolzfus M, Ray B, Holmes H, et al. (2012) Undergraduate college students' perceptions of psychiatric nurses. Issues Ment Health Nurs 33: 769-776.

21. Brohan E, Gauci D, Sartorius N, Thornicroft G, GAMIAN-Europe Study Group (2011) Self-stigma, empowerment and perceived discrimination among people with bipolar disorder or depression in 13 European countries: The GAMIAN-Europe study. J Affect Disord 129: 56-63.

22. Venkataraman S, Patil R, Balasundaram S (2019) Stigma toward mental illness among higher secondary school teachers in Puducherry, South India. J Family Med Prim Care 8: 1401-1407.

23. Arslantaş H, Çalik Koyak H, Sari E (2019) Factors affecting the beliefs toward mental illnesses and social distances of high school students. Cukurova Med J 44: 1272-1283.

24. Moller-Leimkuhler AM, Moller HJ, Maier W, Gaebel W, Falkai $P$ (2016) EPA guidance on improving the image of psychiatry. Eur Arch of Psychiatry Clin Neurosci 266: 139154.

25. Stuart H (2006) Media portrayal of mental illness and its treatments: What effect does it have on people with mental illness? CNS Drugs 20: 99-106.

26. Halter MJ (2002) Stigma in psychiatric nursing. Perspectives in Psychiatric Care 38: 23-28.

27. Agyemang SP, Ninnoni JP (2018) The effects of stigma on mental health nurses: A study at ankaful psychiatric hospital. An International Journal of Nursing and Midwifery 2: 14-20.

28. Gouthro TJ (2009) Recognizing and addressing the stigma associated with mental health nursing: A critical perspective. Issues Ment Health Nurs 30: 669-676.

29. Yin RK (2017) Applications of Case Study Research. Nobel Academic Publishing, Çankaya/Ankara.
30. Ünsal G, Karaca S, Arnik M, Can Öz Y, Aşik E (2014) The opinions of nurses who work in psychiatry clinics related to the roles of psychiatry nurses. Journal of Marmara University Institute of Health Sciences 4: 90-95.

31. Tong A, Sainsbury P, Craig J (2007) Consolidated criteria for reporting qualitative research (COREQ): A 32-item checklist for interviews and focus group. International Journal for Quality in Health Care 19: 349-357.

32. Yildirım A, Şimşek H (2016) Qualitative research methods in the social sciences. Seçkin Publishing.

33. Fusch, PI, Ness LR (2015) Are we there yet? Data saturation in qualitative research. The Qualitative Report 20: 1408-1416.

34. Edwards D, Burnard P, Hannigan B, Cooper L, Adams J, et al. (2006) Clinical supervision and burnout: The influence of clinical supervision for community mental health nurses. $J$ Clin Nurs 15: 1007-1015.

35. Leka S, Hassard J, Yanagida A (2012) Investigating the impact of psychosocial risks and occupational stress on psychiatric hospital nurses' mental well-being in Japan. J Psychiatr Ment Health Nurs 19: 123-131.

36. Hugh ML (2012) Interrater reliability: The kappa statistic. Biochem Med (Zagreb) 22: 276-282.

37. Çam O, Engin E (2006) The effects of self awareness education on the individual performance standards of nurses who work in psychiatry clinic. Anatolian Journal of Psychiatry $7:$ 82-91.

38. Natan M, Droi T, Hochman O (2015) Associative stigma related to psychiatric nursing within the nursing profession. Arch Psychiatr Nurs 29: 388-392.

39. Regulation on the Amendment of the Nursing Regulation (2011) Official newspaper.

40. Özbaş D, Buzlu S (2011) Thoughts of nursing students about psychiatric nursing lesson and roles of the psychiatric nurse. Journal of Anatolian Nursing and Health Sciences 14: 1.

41. Khankeh $H$, Khorasani-Zavareh D, Hoseini SA, Khodai-Ardekandi MR, Ekman SL, et al. (2014) The journey between ideal and real: Experiences of beginners psychiatric nurses. Iran J Nurs Midwifery Res 19: 396-403.

42. Smith AL, Cashwell CS (2010) Stigma and mental illness: Investigating attitudes of mental health and non-mentalhealth professionals and trainees. The Journal of Humanistic Counseling, Education and Development 49: 189-202.

43. Pekriz Ş (2009) Determining the factors affecting the perception of aggression of psychiatric nurses. Istanbul University Health Sciences Institute, Istanbul.

44. Yuan Q, Abdin E, Picco L, Vaingankar JA, Shahwan S, et al. (2016) Attitudes to mental illness and its demographic correlates among general population in Singapore. PLoS One 11: e0167297.

45. Taş Hi, Ertekin $H$ (2018) Evaluation of attitudes and thoughts of fifth grade medical faculty students towards psychiatry before and after psychiatry internship. Fam Pract Palliat Care 3: 18-22.

46. Frueh BC, Knapp RG, Cusack KJ, Grubaugh AL, Sauvageot JA, et al. (2005) Patients' reports of traumatic or harmful experiences within the psychiatric setting. Psychiatr Serv 56: 1123-1133.

47. Zeng JY, An FR, Xiang YT, Qi YK, Ungvari GS, et al. (2013) Frequency and risk factors of workplace violence on psychiatric nurses and its impact on their quality of life in China. Psychiatry Res 210: 510-514. 
48. Hung BJ, Huang XY, Cheng JF, Wei SJ, Lin MJ (2014) The working experiences of novice psychiatric nurses in Taiwanese culture: A phenomenological study. J Psychiatr Ment Health Nurs 21: 536-543.

49. Bilgin H, Buzlu S (2006) A study of psychiatric nurses' beliefs and attitudes about work safety and assaults in Turkey. Issues Ment Health Nurs 27: 75-90.

50. Rime B, Zech E (2001) The social sharing of emotion: Interpersonal and collective dimensions. Boletin de Psicologia 70: 97-108.
51. Meadors P, Lamson A (2008) Compassion fatigue and secondary traumatization: Provider self care on intensive care units for children. J Pediatr Health Care 22: 24-34.

52. Boyle DA (2011) Countering compassion fatigue: A requisite nursing agenda. Online J Issues Nurs 16: 2.

53. Küçük S, Demir K, Uludaşdemir D (2020) Determination of the metaphors about nurse perception of 7-17 age hospitalized children and adolescents. Koç University Journal of Nursing Education and Research 17: 40-45. 